\title{
Analysis of polycyclic aromatic hydrocarbons migrating from polystyrene/divinylbenzene-based food contact materials
}

\author{
Andrea Schweighuber ${ }^{1} \cdot$ Markus Himmelsbach $^{1} \cdot$ Wolfgang Buchberger $^{1} \cdot$ Christian W. Klampfl $^{1}$
}

Received: 18 December 2018 / Accepted: 21 January 2019 / Published online: 29 April 2019

(c) The Author(s) 2019

\begin{abstract}
Single-use utensils made from polystyrene (PS), coming into contact with food or beverages during consumption or storage were analyzed with respect to the presence of polycyclic aromatic hydrocarbons (PAHs). Using the developed sample preparation procedure and high-performance liquid chromatography with fluorescence detection allowed the analysis of 14 PS-based items, thereby detecting several PAHs. Additionally the potential migration of PAHs from the PS material into a food simulant (95\% ethanol) was investigated experimentally. After $24 \mathrm{~h}$ of contact between the PS and the ethanol several PAHs were detected in the food simulant at concentrations in the $\mathrm{ng} \mathrm{cm}^{-3}$ range.
\end{abstract}

\section{Graphical abstract}

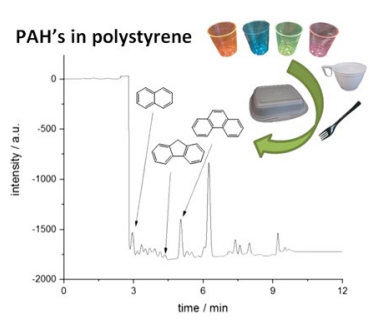

Keywords Food analysis $\cdot$ Food simulants $\cdot$ Polymer analysis $\cdot$ Migration studies $\cdot$ Non-intentionally added substances

\section{Introduction}

Packaging and single-use items such as food containers, plates, cutlery, or cups and beakers are some of the most widely used applications of plastic materials intended for direct contact with food and beverages. Major advantages of plastic materials are their lightweight, versatility, low price, easy fabrication, and inertness towards the packed product. Nevertheless, when plastic is used for food contact products, a series of requirements need to be fulfilled [1, 2]. One issue that has to be considered is the possibility of unwanted migration of substances from the polymer into

Christian W. Klampfl

Christian.klampfl@jku.at

1 Institute of Analytical Chemistry, Johannes Kepler University Linz, Linz, Austria the food-a situation that might be associated with health risks for the consumer. For this reason food contact materials have to be tested for migration [3]. Often the probability that (mainly) low molecular mass components migrate out of the polymer is just estimated by mathematical simulation [4]. However, more reliable data can be obtained by performing actual migration experiments using either real food [5] or (as done in most cases) appropriate food simulants, mimicking aqueous, acidic, alcoholic, or fatty foodstuff [6, 7]. In such studies the migration of intentionally added (such as monomers, additives, plasticizers, and stabilizers just to name a few) but also of non-intentionally added substances (NIAS) is investigated.

Although polyolefines are the most widely used material for food packaging and food containers, also products based on polycarbonates, polyethylene terephthalate, and polystyrene (PS) have to be considered. In recent reports, the presence of polycyclic aromatic hydrocarbons (PAHs) in PS and 
rubber products has been mentioned [8-11]. As these NIAS are known to be toxic, carcinogenic, and mutagenic, their potential migration from PS-based food contact materials (where they are most probably formed during the production process) should be investigated.

In the present study, we used high-performance liquid chromatography (HPLC) with fluorescence detection (HPLC-FD) as well as gas chromatography with mass spectrometric detection (GC-MS) to investigate the presence of PAHs in PS-based products intended for use with foods and beverages. Additionally, these items were tested with respect to the potential migration of the PAHs from PS into a food simulant (95\% ethanol).

\section{Results and discussion}

\section{Analysis of PAHs from PS-based products}

In a first step, the PS-based plastic products (for a closer description see Table 1) were analyzed with respect to the presence of the selected PAHs (for structures see Fig. 1). Starting point for these investigations was knowledge from the previous work in the field of polymer analysis present at the institute as well as a recently published study [9].

The sample was first cut into pieces, dissolved and subsequently the polymer was precipitated. After removal of the precipitate by centrifugation, the total volume of the solution had to be reduced to achieve sufficient sensitivity in the subsequent HPLC-FD or GC-MS analysis. This requires an almost complete removal of the PS during the precipitation step. To achieve this goal, different solvent/solvent mixtures were tested for dissolution and subsequent precipitation of the polymer. The precipitate was removed by centrifugation and the amount of polymer still dissolved in the supernatant

Table 1 PS-based single-use products investigated in this study

\begin{tabular}{lll}
\hline Designation of product & Color & Material \\
\hline Box & White & Extruded PS foam \\
Fork & Black & PS \\
Coffee cup & White & PS \\
Knife & White & PS \\
Beaker & White & PS \\
Glass & Transparent & PS \\
Schnapsglas & Blue (b) & PS \\
& Yellow (y) & \\
& Orange (o) & \\
Skewer & Pink (p) & \\
Soup cup & Yellow & PS \\
Plate & White & Extruded PS foam \\
Thermo cup & White & PS \\
\hline
\end{tabular}

was determined by evaporating the solvent with subsequent weighing of the residual solid material. Table 2 shows an overview of the results from these experiments. As can be seen from this table, dissolution with dichloromethane or dichloromethane/acetone mixtures followed by precipitation with acetonitrile or methanol provided the best results.

To finally decide which precipitation solvent was the better choice, both methanol and acetonitrile were analyzed with respect to contamination with PAHs, whereby the latter solvent showed cleaner chromatograms and was, therefore, selected for the further studies. Comparing GC-MS and HPLC-FD for determining the recoveries (from solutions spiked with the PAHs at a level of $30 \mathrm{ppb}$ each) revealed that the latter method excelled with improved sensitivity and cleaner chromatograms for all solutes. Also limits of detection (LOD) and limits of quantitation (LOQ) were better for the HPLC-FD (LOD: $10-150 \mathrm{ng} \mathrm{dm}^{-3}$ ) method than for GC-MS (LOD: $200-800 \mathrm{ng} \mathrm{dm}^{-3}$ ). This is also due to the fact that a 1:1 dilution of the extract with water allowed increasing the injection volume of the HPLC-FD method to $0.1 \mathrm{~cm}^{3}$. Figure 2 shows the amount of PAHs (as a sum parameter) determined in the investigated PS-based plastic products by HPLC-FD. To evaluate the quality of the proposed method, spiked samples were analyzed at a level of $30 \mu \mathrm{g} \mathrm{kg}^{-1}$ in triplicate leading to recoveries between $100 \%$ (naphthalene) and 78\% (chrysene) with standard deviations below $4 \%$.

Naphthalene (which is not a PAH in a strict sense) was found in all samples as well as acenapthtene, and phenantrene. The party-skewer sample showed the highest total amount - a fact that is mainly due to naphthalene that was found at an extremely high level of $194 \mathrm{ng} \mathrm{g}^{-1}$ in this sample. All samples except the "Schnapsglas" also contained fluorene; a similar situation was encountered for pyrene whereby this PAH was found in the orange "Schnapsglas" at a relatively high concentration $\left(60 \mathrm{ng} \mathrm{g}^{-1}\right)$ - a fact that might be associated with the dye used for the coloring. Fluoranthene was only found in three samples ("Schnapsglas" pink, party-skewer, plate).

\section{Investigations on the migration of PAHs from PS into food simulants}

Whereas in the previous work migration of PAHs from PS food contact materials was only estimated based on theoretical calculations [9], in the present paper migration was studied experimentally. For migration experiments $6 \mathrm{~cm}^{2}$ of each PS-product were immersed in three $\mathrm{cm}^{3}$ of $95 \%$ ethanol, which is a typical simulant for fatty foodstuff [12], using closed glass vessels and stored for $24 \mathrm{~h}$ at room temperature. Again, for evaluation of the method quality, solutions of ethanol were spiked with the PAHs at a level of $5 \mathrm{\mu g} \mathrm{dm}^{-3}$ and analyzed in triplicate. Recoveries found were between $90 \%$ 
Fig. 1 Structures of the investigated PAHs<smiles>c1ccc2ccccc2c1</smiles>

Naphthalene (Nap), $\mathrm{C}_{10} \mathrm{H}_{8}$<smiles>c1cc2c3c(cccc3c1)CC2</smiles>

Acenaphthene (Ace), $\mathrm{C}_{12} \mathrm{H}_{10}$<smiles>c1ccc2cc3ccccc3cc2c1</smiles>

Anthracene (Ant), $\mathrm{C}_{14} \mathrm{H}_{10}$<smiles></smiles>

Pyrene (Pyr), $\mathrm{C}_{16} \mathrm{H}_{10}$<smiles>c1ccc2c(c1)ccc1c3ccccc3ccc21</smiles>

Chrysene (Chr), $\mathrm{C}_{18} \mathrm{H}_{12}$<smiles></smiles>

Benzo[b]fluoranthene (BbF), $\mathrm{C}_{20} \mathrm{H}_{12}$<smiles>c1ccc2cc3ccc4c5ccccc5c5cc(c1)c4c3c25</smiles>

Indeno[1,2,3-cd]pyrene (InP), $\mathrm{C}_{22} \mathrm{H}_{12}$

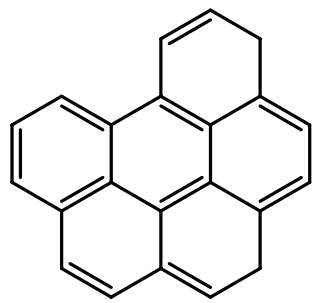

Benzo[ghi]perylene (Bp), $\mathrm{C}_{22} \mathrm{H}_{12}$<smiles>c1ccc2c(c1)Cc1ccccc1-2</smiles>

Fluorene (Fle), $\mathrm{C}_{13} \mathrm{H}_{10}$<smiles></smiles>

Acenaphthylene (Acy), $\mathrm{C}_{12} \mathrm{H}_{8}$<smiles>c1ccc2c(c1)ccc1ccccc12</smiles>

Phenanthrene (Phe), $\mathrm{C}_{14} \mathrm{H}_{10}$<smiles>c1ccc2c(c1)-c1cccc3cccc-2c13</smiles>

Fluoranthene (Flu), $\mathrm{C}_{16} \mathrm{H}_{10}$<smiles>c1ccc2cc3c(ccc4ccccc43)cc2c1</smiles>

Benzo[a]anthracene (BaA), $\mathrm{C}_{18} \mathrm{H}_{12}$<smiles>c1ccc2c(c1)cc1ccc3cccc4ccc2c1c34</smiles>

Benzo[a]pyrene (BaP), $\mathrm{C}_{20} \mathrm{H}_{12}$<smiles>c1ccc2c(c1)ccc1cc3c(ccc4ccccc43)cc12</smiles>

Dibenzo[a, $h$ ]anthracene (DBA), $\mathrm{C}_{22} \mathrm{H}_{14}$ 
Table 2 Remaining dissolved polymer after dissolution of $2 \mathrm{~g}$ of a PS-based product followed by precipitation with an appropriate solvent and centrifugation

\begin{tabular}{llc}
\hline Solvent for dissolution & Solvent for precipitation & $\begin{array}{r}\text { Residual } \\
\text { mass/mg }\end{array}$ \\
\hline DCM & $n$-Hexane & 216.1 \\
DCM/acetone (3:1) & & 139.7 \\
DCM/acetone (1:1) & & 23.7 \\
THF & & 83.4 \\
DCM & Acetonitrile & 3.0 \\
DCM/acetone (3:1) & & 2.7 \\
DCM/acetone (1:1) & & 2.5 \\
THF & Methanol & 11.4 \\
DCM & & 1.8 \\
DCM/acetone (3:1) & & 1.4 \\
DCM/acetone (1:1) & & 2.4 \\
THF & & 7.9 \\
\hline
\end{tabular}

$D C M$ dichloromethane, $T H F$ tetrahydrofuran

(naphthalene) and 45\% (phenantrene). Standard deviations were higher compared to those obtained for the analysis of the PS materials, ranging between 2 and $15 \%$.

Figure 3 shows a HPLC-FD chromatogram from the migration experiments related to the party-skewer (A) and the box (B). As can be seen from this chromatogram similar amounts of PAHs migrated from the box compared to the party-skewer. Only at first sight this might be understood as a contradiction to the data in Table 3 , showing substantially higher values for the box. This can be explained by the fact that the data given in the Table are in $\mathrm{ng} \mathrm{g}^{-1}$. Here the substantially lower density of the PS foam of the box $\left(6 \mathrm{~cm}^{2}-40 \mathrm{mg}\right)$ compared to the more solid skewer $\left(6 \mathrm{~cm}^{2}-250 \mathrm{mg}\right)$ results in a distinct difference in weight for the pieces used for the migration experiments.
This might be explained by the fact that extruded PS foam provides a larger surface area as the solvent can penetrate into the pores of the material. As only minor amounts of PAHs were expected to migrate into the solvent, blank values for the solvent had to be determined first, so they could be subtracted from the results obtained during the migration experiments. For this reason $10 \mathrm{~cm}^{3}$ of ethanol were reduced to $1 \mathrm{~cm}^{3}$ by vacuum distillation and subjected to HPLC-FD, resulting in the detection of marginal amounts of naphthalene $\left(0.3 \mu \mathrm{g} \mathrm{dm}^{-3}\right)$, acenapthtene $\left(0.2 \mu \mathrm{g} \mathrm{dm}^{-3}\right)$, and phenantrene $\left(0.1 \mu \mathrm{g} \mathrm{dm}^{-3}\right)$ in the $95 \%$ ethanol. An overview of the amounts of PAHs determined in the food simulant after being in contact with the respective PS-product for $24 \mathrm{~h}$ is depicted in Table 3 (left columns). Additionally the results from this analysis were compared with the amount of PAH found in the PS-product, thereby determining the percentage of PAH migrating from the product into the simulant (right columns). The data presented in this table also reveal that there is a substantial difference between normal PS-products and those produced from PS foam. For the latter not only an increased amount of PAHs is found in the simulant, but also a higher percentage of PAH present in the material migrates into the ethanol.

\section{Conclusion}

A number of PS-based single-use products intended for contact with food and beverages were investigated with respect to the presence of PAHs in the material. In addition these products were brought into contact with a food simulant commonly used for mimicking fatty or alcoholic food (95\% ethanol) to study the potential migration of the PAHs from the PS into the simulant. For three of the tested products a total migration (i.e., sum of all PAHs investigated) of more
Fig. 2 Total amount of PAHs in the investigated food contact materials determined by HPLCFD. Error bars express standard deviation from three measurements

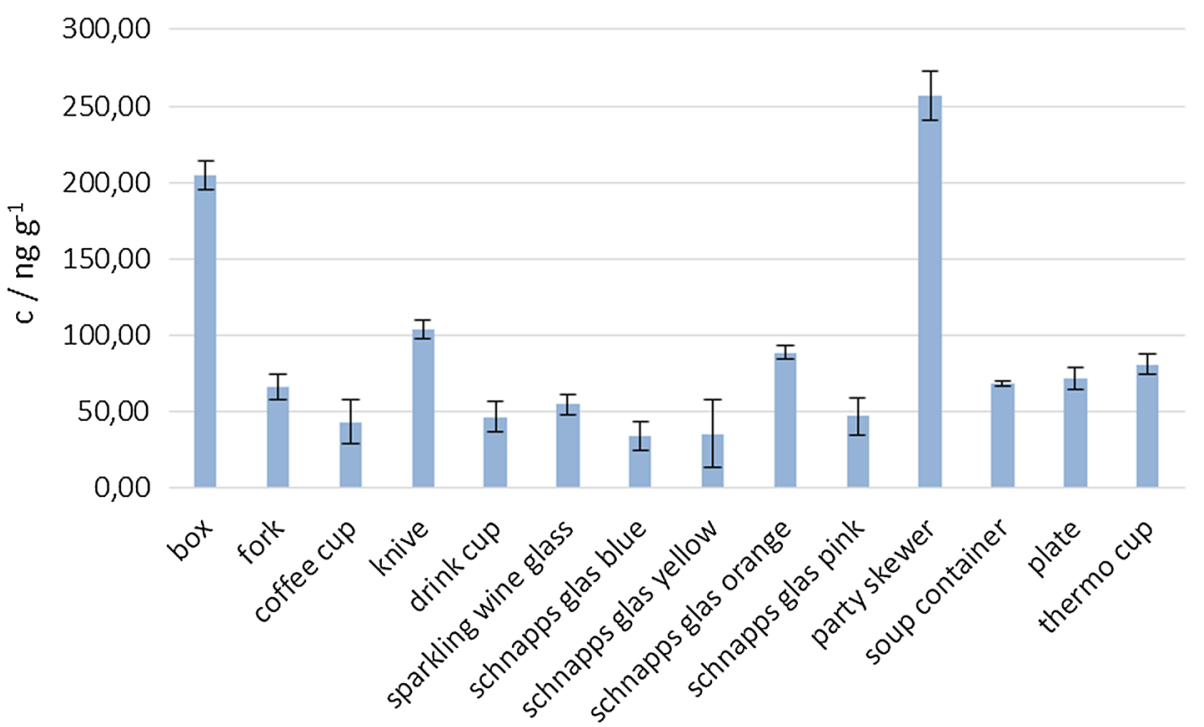



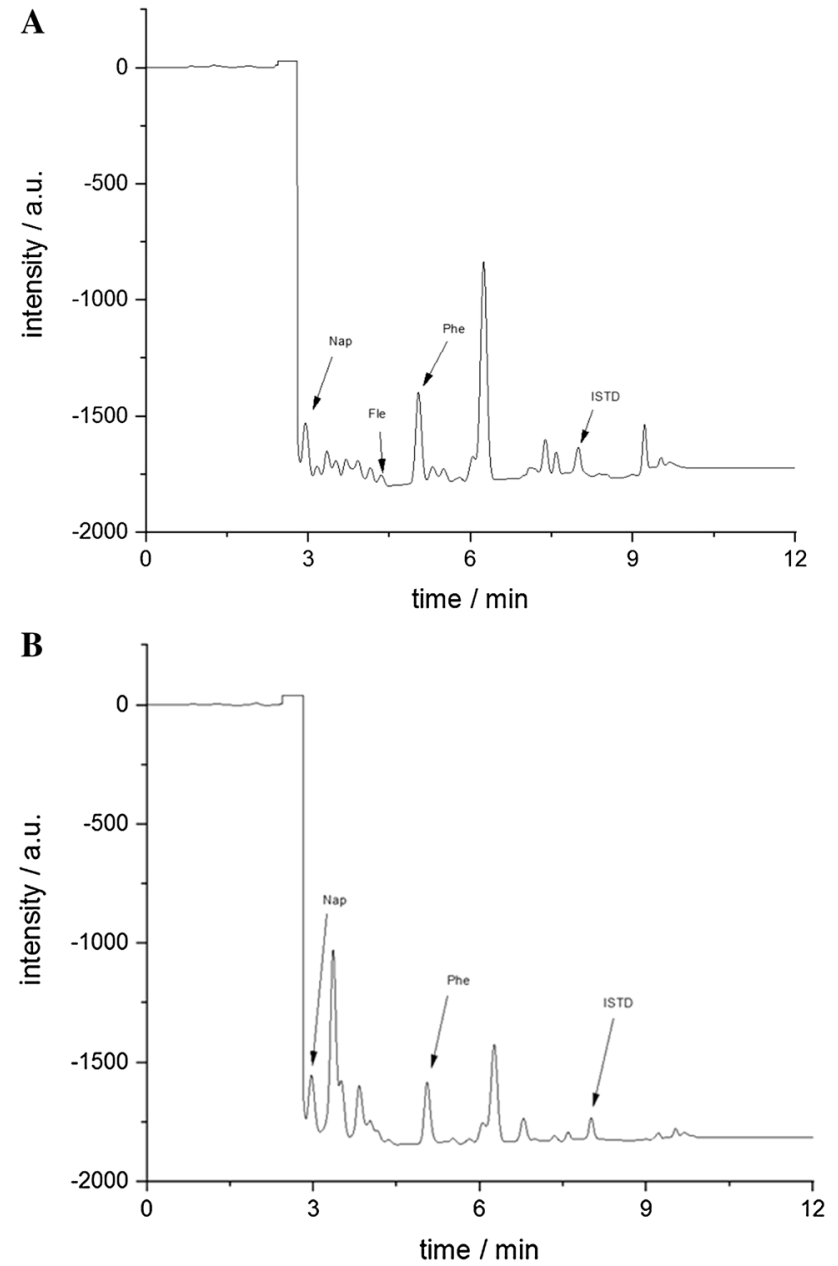

Fig. 3 HPLC-FD chromatograms from simulant solutions (95\% ethanol) brought into contact with party-skewer (a) and box (b) for $24 \mathrm{~h}$ at room temperature. For details see "Experimental"

than $10 \mathrm{ng} \mathrm{g}^{-1}$ was detected. Nevertheless it should be taken into account that these three products were all produced from extruded PS foam, so the migration test was conducted with a substantially higher accessible surface - a fact that might be an explanation for these relatively high values.

\section{Experimental}

PS-based food contact materials were purchased from local supermarkets and used without any further pre-treatment.

HPLC-FD chromatography was performed using an Agilent 1220 modular HPLC system (Agilent Technologies, Waldbronn Germany) equipped with a G1315 diode array UV detector and a G1321A fluorescence detector. A Kinetex $3.5 \mu \mathrm{m}$ PAH column $(100 \times 4.6 \mathrm{~mm})$ (Phenomenex, Aschaffenburg, Germany) was employed. The following linear gradient was operated for elution: 0-1.5 min: acetonitrile/ water (40/60); 1.5-4.5 min: acetonitrile/water (50/50); 4.5-11.5 min: acetonitrile/water (50/50); 11.5-12.0 min: acetonitrile/water (100/0). $0.1 \mathrm{~cm}^{3}$ of sample (diluted with water 1:1) was injected for each HPLC run. Wavelengths for excitation (Ex) and emission (Em) were programmed during the HPLC run to detect the solutes at the optimum wavelength combination. The following program was used: 2.5-4.9 $\min (270 \mathrm{~nm} \mathrm{Ex/330} \mathrm{nm} \mathrm{Em}$ ) for naphthalene; 4.9-6.5 $\mathrm{min}(250 \mathrm{~nm} \mathrm{Ex/370} \mathrm{nm} \mathrm{Em})$ for acenaphthalene and fluorene; $6.5-7.25 \mathrm{~min}(237 \mathrm{~nm} \mathrm{Ex} / 440 \mathrm{~nm} \mathrm{Em})$ for phenantrene and anthracene; 7.25-7.9 $\min (270 \mathrm{~nm} \mathrm{Ex/390} \mathrm{nm}$ Em) for fluoranthene and pyrene; 7.9-8.7 $\min (226 \mathrm{~nm}$ $\mathrm{Ex} / 393 \mathrm{~nm} \mathrm{Em}$ ) for 2,6-diethylnaphthalene (internal standard); 8.7-9.6 $\min (270 \mathrm{~nm} \mathrm{Ex/390} \mathrm{nm} \mathrm{Em})$ for benzo[a] anthracene and chrysene; 9.6-10.5 min (260 nm Ex/450 nm Em) for benzo[b]fluoranthene; $10.5-11.0 \mathrm{~min}(260 \mathrm{~nm}$ $\mathrm{Ex} / 410 \mathrm{~nm} \mathrm{Em}$ ) for dibenzo[ $a, h]$ anthracene; $11.0-15 \mathrm{~min}$ (290 nm Ex/420 nm Em) for benzo[ghi]perylene.

GC-MS was performed using an Agilent 6890 N Network GC with an Agilent 5975C Inert XL MSD mass spectrometric detector operated in the selected ion monitoring mode and a J\&W Select PAH GC-column $(30 \mathrm{~m} \times 0.25 \mathrm{~mm} \times 0.15 \mu \mathrm{m})$. The temperature program was as follows: $70^{\circ}$ isotherm for $2 \mathrm{~min}$; up to $130^{\circ}$ with $15^{\circ} \mathrm{min}^{-1}$, than up to $250^{\circ}$ with $20^{\circ} \mathrm{min}^{-1}$ followed by heating to the final temperature $\left(320^{\circ}\right)$ at a rate of $10^{\circ} \mathrm{min}^{-1}$. The following detection parameters were selected at the MS: $6.0-8.5 \mathrm{~min}(\mathrm{~m} / z=127.1,128.1)$ for naphthalene; $8.5-10.3 \mathrm{~min}(\mathrm{~m} / \mathrm{z}=151.1,152.1,153.1,154.2)$ for acenaphthalene; $10.3-10.85 \mathrm{~min}(\mathrm{~m} / \mathrm{z}=183.3,184.3)$ for 2,6-diethylnaphthalene (internal standard); 10.85-11.5 min $(m / z=165.1,166.1)$ for fluoranthene; $11.5-13.8 \mathrm{~min}$ $(m / z=176.1,178.1)$ for phenantrene and anthracene; 13.8-16.5 $\mathrm{min}(\mathrm{m} / \mathrm{z}=200.1,202.1)$ for fluoranthene and pyrene; $16.5-19.4 \mathrm{~min}(\mathrm{~m} / \mathrm{z}=226.1,228.1)$ for benzo[ $a]$ anthracene and chrysene; $19.4-22.0 \mathrm{~min}(\mathrm{~m} / \mathrm{z}=250.1$, $252.1)$ for benzo[ $b]$ fluoranthene and benzo $[a]$ pyrene; from $22.0 \mathrm{~min}(\mathrm{~m} / \mathrm{z}=274.1,276.1,278.1)$ for benzo[ $\mathrm{ghi}]$ perylene, dibenzo[ $[a, h]$ anthracene, and indeno[1,2,3-cd]pyrene.

\section{Sample preparation and migration experiments}

For PAH analysis in PS food contact materials $2.0 \mathrm{~g}$ of sample was cut into small pieces, immersed in $10 \mathrm{~cm}^{3}$ of the appropriate solvent (see Table 2) and placed in an ultrasonic bath for $30 \mathrm{~min}$. Subsequently, the polymer was precipitated with $10 \mathrm{~cm}^{3}$ of an appropriate solvent (see Table 2) and centrifugation at $4000 \mathrm{rpm}$ was performed for $20 \mathrm{~min}$. The supernatant was reduced to approximately $1 \mathrm{~cm}^{3}$ and analyzed after addition of the internal standard (2,6-diethylnaphthalene).

For migration experiments $6 \mathrm{~cm}^{2}$ of the PS food contact material was cut into pieces and placed together with $3 \mathrm{~cm}^{3}$ 
Table 3 Migration of PAHs into $95 \%$ ethanol. Left columns: amount determined in the simulant per gram of PS-product immersed in the simulant. Right columns: percentage of PAHs that migrated (in relation to amount found in the intact PS-product)

\begin{tabular}{|c|c|c|c|c|c|c|c|c|c|c|}
\hline & \multicolumn{2}{|l|}{ Nap } & \multicolumn{2}{|l|}{ Ace } & \multicolumn{2}{|l|}{ Phe } & \multicolumn{2}{|l|}{ Pyr } & \multicolumn{2}{|l|}{ Total } \\
\hline & $\mathrm{ng} \mathrm{g}^{-1}$ & $\%$ & $\mathrm{ng} \mathrm{g}^{-1}$ & $\%$ & $\mathrm{ng} \mathrm{g}^{-1}$ & $\%$ & $\mathrm{ng} \mathrm{g}^{-1}$ & $\%$ & $\mathrm{ng} \mathrm{g}^{-1}$ & $\%$ \\
\hline Box & 35 & 30 & n.d. & - & 13 & 20 & n.d. & - & 48 & 23 \\
\hline Fork & $<0.5$ & - & n.d. & - & 2 & 22 & n.d. & - & 2 & 4 \\
\hline Coffee cup & 1 & 3 & n.d. & - & 1 & 14 & n.d. & - & 2 & 4 \\
\hline Knife & 1 & 1 & n.d. & - & $<0.5$ & - & n.d. & - & 1 & 2 \\
\hline Beaker & n.d. & - & n.d. & - & n.d. & - & n.d. & - & - & - \\
\hline Glass & 1 & 5 & n.d. & - & 3 & 10 & n.d. & - & 4 & 7 \\
\hline Schnapsglas-b & 1 & 2 & n.d. & - & 2 & $-^{\mathrm{a}}$ & n.d. & - & 3 & 7 \\
\hline Schnapsglas-y & n.d. & - & 1 & 9 & 3 & $-^{\mathrm{a}}$ & n.d. & - & 7 & 19 \\
\hline Schnapsglas-o & n.d. & - & n.d. & - & n.d. & - & n.d. & - & - & - \\
\hline Schnapsglas-p & $<0.5$ & - & n.d. & - & n.d. & - & n.d. & - & - & - \\
\hline Skewer & 1 & 1 & n.d. & - & 4 & 10 & n.d. & - & 5 & 2 \\
\hline Soup cup & 19 & 51 & n.d. & - & 15 & 65 & n.d. & - & 34 & 49 \\
\hline Plate & 1 & 2 & n.d. & - & 1 & 13 & n.d. & - & 2 & 3 \\
\hline Thermo cup & 25 & 39 & n.d. & - & n.d. & - & n.d. & - & 25 & 30 \\
\hline
\end{tabular}

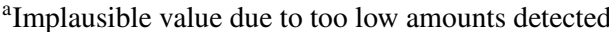

of ethanol (95\%) in a headspace vial that was finally closed and stored at room temperature for $24 \mathrm{~h}$. For the PS foam materials, to guarantee sufficient contact with the simulant a piece of metal had to be used for weighting. Subsequently, the solution was analyzed by GC-MS or HPLC-FD.

Acknowledgements Open access funding provided by Johannes Kepler University Linz. The authors would like to thank DI Markus Wierer for fruitful discussions during the planning of the experimental work.

Open Access This article is distributed under the terms of the Creative Commons Attribution 4.0 International License (http://creativeco mmons.org/licenses/by/4.0/), which permits unrestricted use, distribution, and reproduction in any medium, provided you give appropriate credit to the original author(s) and the source, provide a link to the Creative Commons license, and indicate if changes were made.

\section{References}

1. Castillo M, Borrell A (2018) Curr Anal Chem 14:358

2. Hahladakis JN, Velis CA, Weber R, Iacovidou E, Purnell P (2018) J Hazard Mater 344:179
3. Sanchisa Y, Yusà V, Coscollà C (2017) J Chrom A 1490:22

4. Gavriil G, Kanavouras A, Coutelieris FA (2018) Crit Rev Food Sci Nutr 58:2262

5. Bodai Z, Szabo BS, Novak M, Hamori S, Nyiri Z, Rikker T, Eke Z (2014) J Agric Food Chem 62:10028

6. Martinez-Bueno MJ, Gomez Ramos MJ, Bauer A, FernandezAlba AR (2019) TrAC Trends Anal Chem 10:191

7. Emhofer L, Klampfl CW, Buchberger W (2016) Curr Anal Chem 12:108

8. Rochmann CM, Manzano C, Hentschel BT, Simonich SL, Hoh E (2013) Environ Sci Technol 47:13976

9. Li S-Q, Ni H-G, Zeng H (2017) Sci Total Environ 609:1126

10. Geiss O, Senaldi C, Bianchi I, Lucena A, Tirendi S, BarreroMoreno J (2018) J Chromotogr A 1566:13

11. Bohrer D, Viana C, Barichello MM, de Moura JF, Carvalho LM, Nascimento PC (2016) J Parent Ent Nutr 41:1037

12. Commission Regulation (EU) no 10/2011 of January 2011 on plastic materials and articles intended to come into contact with food

Publisher's Note Springer Nature remains neutral with regard to jurisdictional claims in published maps and institutional affiliations. 